\title{
IL-8 mRNA expression in the mouse mammary glands during pregnancy and lactation
}

\author{
H.P. Li*, Y.J. Guo*, H.S. Zhu, K. Zhong, G.M. Zha, L.F. Wang, \\ Y.L. Wang, W.F. Lu, Y.Y. Wang and G.Y. Yang
}

Key Laboratory of Animal Biochemistry and Nutrition, Ministry of Agriculture, Henan Agricultural University, Zhengzhou, Henan, China

*These authors contributed equally to this study. Corresponding authors: Y.Y. Wang / G.Y. Yang

E-mail: wangyueying2008@126.com / haubiochem@163.com

Genet. Mol. Res. 11 (4): 4746-4753 (2012)

Received June 20, 2012

Accepted August 29, 2012

Published October 9, 2012

DOI http://dx.doi.org/10.4238/2012.October.9.10

\begin{abstract}
Interkeukin-8 (IL-8) is an important inflammatory mediator. It is an angiogenic factor associated with inflammation and carcinogenesis. To date, research on IL-8 has been limited to its role as an indicator of inflammation. There has been no systematic research concerning IL-8 expression levels in the mouse mammary gland during pregnancy and lactation. Mouse mammary gland samples were collected on days $1,6,12,18$ of pregnancy and of lactation (6 mice per group). The expression levels of IL- 8 mRNA were measured by semi-quantitative RT-PCR, with GAPDH as an internal control. IL-8 mRNA was highly expressed on day 1 of pregnancy in the mouse mammary glands $\left(\mathrm{IL}-8_{\mathrm{IOD}} / \mathrm{GAPDH}_{\mathrm{IOD}}=1.68\right)$, and then suddenly declined; it reached 0.74 and 0.71 on days 6 and 12 of pregnancy. On day 18 of pregnancy, it started to increase (IL- $8_{\text {IOD }} / \mathrm{GAPDH}_{\mathrm{IOD}}$ $=1.02)$. However, the expression levels of IL-8 mRNA were not significant during pregnancy. During lactation, IL-8 expression level was lower than during pregnancy, but it stabilized at 0.32-0.41 (IL$8_{\text {IOD }} / \mathrm{GAPDH}_{\mathrm{IOD}}$ ) from day 1 to day 18 of lactation, although the difference was not significant. We suggest that the changes in IL-8
\end{abstract}


expression level during development is related to its regulatory role in mouse mammary gland immunity.

Key words: IL-8; Mouse; Mammary gland; Pregnancy; Lactation

\section{INTRODUCTION}

Cytokines are produced by leukocytes in response to exposure to bacterial toxins or inflammatory mediators (Dinarello, 1989). Cytokines are multifunctional proteins and glycoproteins that act as intercellular regulatory factors at both local and systemic levels. Chemokines are members of a superfamily of chemotactic cytokines that function as potent chemoattractants for various cell types in the immune system. Four subclasses of chemokines can be classified according to the location of the first two cysteines in their sequence: CC, CXC, C, and CX3C (in which X stands for any amino acid) (Kaplan, 2001). Some chemokines are expressed constitutively by many cell types in a tissue-specific manner. The expression of other chemokines is induced only under specific conditions, typically in response to inflammatory signals (Hallgren and Gurish, 2011).

Interkeukin-8 (IL-8) is an important inflammatory mediator belonging to the CXC subfamily of chemokines. It acts as both a cytokine and a chemokine by recruiting neutrophils to sites of infection and activating them to eliminate pathogens via phagocytosis (Taub and Oppenheim, 1994; Ben-Baruch et al., 1995). IL-8 is produced by monocytes and macrophages as well as by most tissues (Baggiolini et al., 1994). IL-8 is induced by a number of stimuli, including pro-inflammatory cytokines (Hoffmann et al., 2002). However, IL-8 has biological functions distinct from its role in regulating inflammatory responses. IL-8 is an angiogenic factor associated with inflammation and carcinogenesis, and previous reports have documented elevated urinary protein levels of IL-8 in subjects with urothelial cell carcinoma (Sheryka et al., 2003; Koçak et al., 2004; Sagnak et al., 2009). In biological studies, IL-8 has been shown to have mitogenic and angiogenic properties, and high levels result in increased tumorigenicity, progression, and metastasis in mouse models (Baggiolini, 2001). In addition, IL-8 is associated with insulin resistance and obesity (Bek et al., 2002; Bruun et al., 2003).

Mammary gland immunity, defined as the protection and resistance to infectious disease, is facilitated through a variety of immunological and nonimmunological factors. Although both factors interact extensively to provide adequate protection against mastitis, the magnitude, duration, and effectiveness of mammary gland immunity are influenced greatly by particular etiological agents (Sordillo and Streicher, 2002). Since 1990, the study of these agents has extended to cytokines and their potential roles in the pathophysiology and control of mastitis. Moreover, recombinant cytokines have been produced to explore their immunomodulatory and therapeutic uses for disease control (Sabroe et al., 2002). To date, research on IL-8 has been limited simply to its role as an indicator of inflammatory. No systematic research of IL-8 expression levels in mouse mammary glands during pregnancy and lactation has been undertaken. We used mouse mammary glands to determine the expression of IL-8 messenger RNA (mRNA) throughout the developmental cycle of the mammary gland and to elucidate the impact and mechanism of IL-8 in mammary gland immunity during pregnancy and lactation with semi-quantitative reverse transcription-polymerase chain reaction (RT-PCR). 


\section{MATERIAL AND METHODS}

\section{Animals and treatment}

Eight-week-old Kunming mice were obtained from the Centre for Laboratory Animals of Henan Province. Animals were maintained in group cages under controlled temperature $\left(25^{\circ}\right.$ $\pm 1^{\circ} \mathrm{C}$ ) and on a 12-h light-dark cycle), with ad libitum access to food and water. At 10 weeks, females were mated. Pregnant animals were monitored daily to define the day of lactation. At postpartum, a minimum of 6 pups per suckling female were ensured by cross fostering where appropriate. Lactating mammary glands were monitored daily for signs of localized inflammation or mastitis. All procedures were approved by the Local Animal Ethics Committee.

\section{Harvesting mammary glands}

Eight stages of adult mouse developmental mammary glands were selected for this study: days 1 (P1), 6 (P6), 12 (P12), and 18 (P18) of pregnancy (in which day 1 was the first day post-coitum), and days 1 (L1), 6 (L6), 12 (L12), and 18 (L18) of lactation (in which day 1 was the second day postpartum). All mammary glands were harvested between 1100 and 1300 to limit circadian effects. A total of six animals were used per time point. In each case, a single abdominal gland was removed following the excision of lymph nodes and immediately frozen in liquid nitrogen.

\section{RNA extraction and reverse transcription}

Total RNA was extracted from the mouse mammary glands with a TRIzol reagent kit (Invitrogen Inc., Carlsbad, CA, USA) and used to determine IL-8 mRNA expression with RT-PCR. All extracted RNA samples were dissolved in RNase-free water. The purity of the dissolved RNA was assessed using an $\mathrm{A}_{260} / \mathrm{A}_{280} \mathrm{~nm}$ ratio measured with an ultraviolet/visible spectrophotometer (Nanodrop 2000/2000C, USA). The integrity of the RNA was determined via denaturing agarose gel electrophoresis. Total RNA was extracted following a conventional protocol and dissolved in $20 \mu \mathrm{L}$ RNase-free water.

RNA was reverse transcribed with a reaction mixture containing $6.5 \mu \mathrm{L}$ diethylpyrocarbonate- $\mathrm{H}_{2} \mathrm{O}, 4 \mu \mathrm{L} 5 \mathrm{X}$ buffer, $4 \mu \mathrm{L} 2.5 \mathrm{mM}$ deoxyribonucleotide triphosphates, $1 \mu \mathrm{L} 50 \mathrm{pM}$ Oligo(dT) $18,2 \mu \mathrm{L} 5 \mathrm{U} / \mu \mathrm{L}$ AMV, $0.5 \mu \mathrm{L} 40 \mathrm{U} / \mu \mathrm{L}$ RNase inhibitor, and $2 \mu \mathrm{L}$ RNA. The total reaction volume was $20 \mu \mathrm{L}$. After gentle mixing, the solution was incubated for $60 \mathrm{~min}$ at $42^{\circ} \mathrm{C}$ and then for $15 \mathrm{~min}$ at $72^{\circ} \mathrm{C}$, followed by $2 \mathrm{~min}$ in an ice bath. Two controls were included in the RT reaction: one prepared using all reagents except the RNA sample, for which an equivalent volume of water was substituted, and the other prepared using all reagents except RT. The controls underwent PCR procedures identical to those of the experimental samples. The complementary DNA product was stored at $-20^{\circ} \mathrm{C}$.

\section{RT-PCR}

The primers used for amplification of IL-8 mRNA were determined using Primer Premier $^{\mathrm{TM}}$ Version 5.0 (Premier Biosoft International, Canada) and checked with the Basic Local Alignment Search Tool. All of the primers, including those for the glyceraldehyde- 
3-phosphate dehydrogenase (GAPDH) gene as an internal reference, were synthesized by Shanghai Sango Biological Engineering Technology \& Services Co. Ltd. (China). Electrophoresis on $1.2 \%(\mathrm{w} / \mathrm{v})$ agarose gels was conducted to determine the quality and integrity of the primers. The sequence of primers and product sizes were as follows: IL-8, sense 5'-cacctcaagaacatccagagct-3', antisense 5'-caagcag aactgaactaccatcg-3', product $356 \mathrm{bp}$; GAPDH, sense 5'-tgcaccaccaactgcttag-3', antisense 5'-gatgcagggatgatgttc-3', product $175 \mathrm{bp}$.

The complementary DNAs obtained were further amplified using PCR in a $25-\mu \mathrm{L}$ mixture consisting of $1 \mu \mathrm{L}$ RT reaction solution, $12.5 \mu \mathrm{L} 2 \mathrm{X}$ Master mix (Shanghai Wonhon Biotechnology Company), $1 \mu \mathrm{L} 20 \mathrm{pM}$ forward primer, $1 \mu \mathrm{L} 20 \mathrm{pM}$ reverse primer, and $9.5 \mu \mathrm{L}$ sterilized $\mathrm{H}_{2} \mathrm{O}$. The reaction substrates were mixed by gently flicking the bottom of each tube. PCR amplification was carried out for 35 cycles $\left(95^{\circ} \mathrm{C}\right.$ for $30 \mathrm{~s} ; 53.6^{\circ} \mathrm{C}$ for $30 \mathrm{~s} ; 72^{\circ} \mathrm{C}$ for 30 s) for GAPDH and 35 cycles $\left(95^{\circ} \mathrm{C}\right.$ for $30 \mathrm{~s} ; 55.6^{\circ} \mathrm{C}$ for $30 \mathrm{~s} ; 72^{\circ} \mathrm{C}$ for $\left.30 \mathrm{~s}\right)$ for IL-8. Reactions were completed with a final extension at $72^{\circ} \mathrm{C}$ for $10 \mathrm{~min}$. For each $5-\mu \mathrm{L}$ sample, PCR amplification products were mixed gently with $3 \mu \mathrm{L}$ fluorochrome, protected from light for 10 min, and then visualized on 1.2\% agarose gel with a Multilmage Light System (Shanghai Tianneng Biotechnology Company).

\section{Statistical analyses}

All results are reported as means \pm standard deviation and analyzed with SPSS (version 13.0, IBM). Differences between group data were analyzed using the Student-NewmanKeuls post hoc test of one-way analysis of variance, and differences between groups were evaluated using the paired-sample $t$-test. Significance was set at $\mathrm{P}<0.05$ and $\mathrm{P}<0.01$, respectively, in two-tailed testing.

\section{RESULTS}

Gel electrophoresis showing the RT-PCR of IL-8 in mouse mammary glands indicated that a single-PCR product of approximately $356 \mathrm{bp}$ was obtained in all samples (Figures 1 and 2). The relative expression levels of IL- 8 mRNA in mouse mammary glands during pregnancy and lactation are shown in Tables 1 and 2 and Figures 3 and 4.

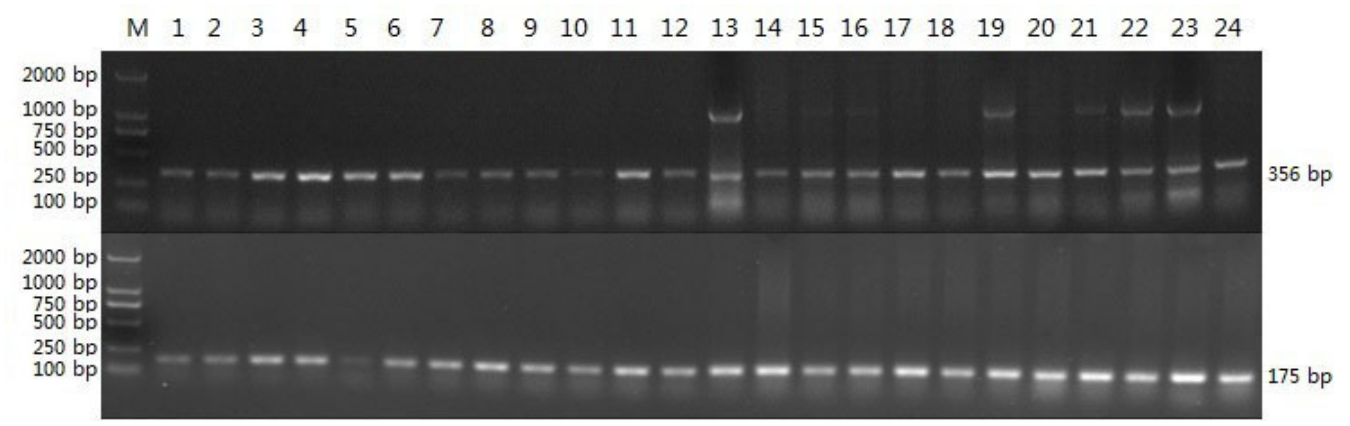

Figure 1. Gel electrophoresis of RT-PCR products in mouse mammary gland during pregnancy. Lane $M=$ molecular marker; lanes 1 to $6=\mathrm{P} 1$; lanes 7 to $12=\mathrm{P} 6$; lanes 13 to $18=\mathrm{P} 12$; lanes 19 to $24=\mathrm{P} 18$. P1, $\mathrm{P} 6$, P12, and $\mathrm{P} 18=$ days $1,6,12$, and 18 of pregnacy, respectively. 
$\begin{array}{lllllllllllllllllllllllll}M & 1 & 2 & 3 & 4 & 5 & 6 & 7 & 8 & 9 & 10 & 11 & 12 & 13 & 14 & 15 & 16 & 17 & 18 & 19 & 20 & 21 & 22 & 23 & 24\end{array}$

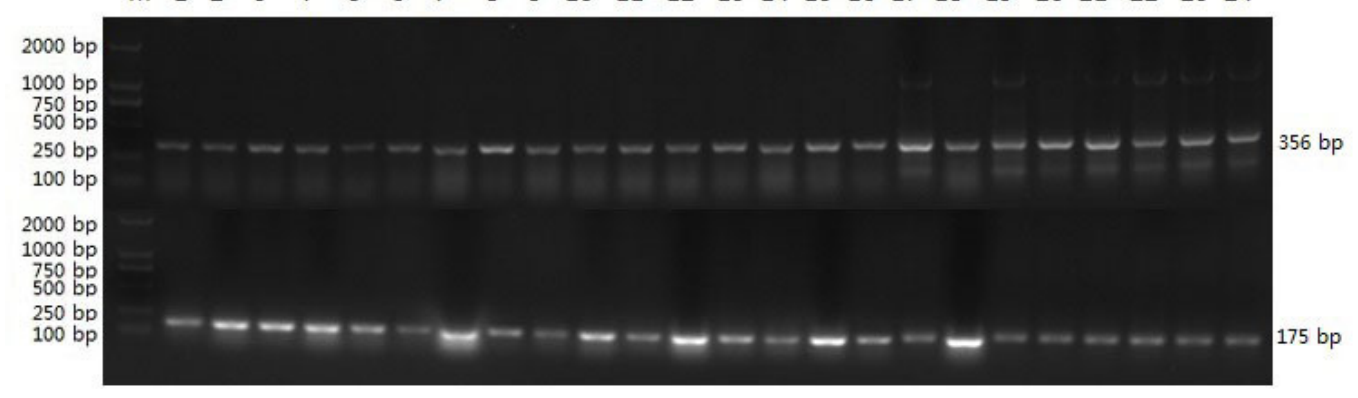

Figure 2. Gel electrophoresis of RT-PCR products in mouse mammary gland during lactation. Lane $M=$ molecular marker; lanes 1 to $6=\mathrm{L} 1$; lanes 7 to $12=\mathrm{L} 6$; lanes 13 to $18=\mathrm{L} 12$; lanes 19 to $24=\mathrm{L} 18$. L1, L6, L12, and L18= days $1,6,12$, and 18 of lactation, respectively.

Table 1. Expression level of IL-8 mRNA relative to GAPDH in mouse mammary gland during pregnancy.

\begin{tabular}{lcc}
\hline Group & No. of samples & IL-8/GAPDH (IOD) \\
\hline P1 & 6 & $1.68 \pm 0.3^{\mathrm{a}}$ \\
P6 & 6 & $0.74 \pm 0.24^{\mathrm{b}}$ \\
P12 & 6 & $0.71 \pm 0.32^{\mathrm{b}}$ \\
P18 & 6 & $1.02 \pm 0.26^{\mathrm{b}}$ \\
\hline
\end{tabular}

P1, P6, P12, and P18 = days 1, 6, 12, and 18 of pregnacy, respectively; IOD = internal optical density. Data in the same column with different superscript letters mean significant differences $(\mathrm{P}<0.05)$.

Table 2. Expression level of IL- 8 mRNA relative to GAPDH in mouse mammary gland during lactation.

\begin{tabular}{lcc}
\hline Group & No. of samples & IL-8/GAPDH (IOD) \\
\hline L1 & 6 & $0.39 \pm 0.09$ \\
L6 & 6 & $0.47 \pm 0.28$ \\
L12 & 6 & $0.32 \pm 0.17$ \\
L18 & 6 & $0.41 \pm 0.16$ \\
\hline
\end{tabular}

L1, L6, L12, and L18 = days 1, 6, 12, and 18 of lactation, respectively; IOD = internal optical density.

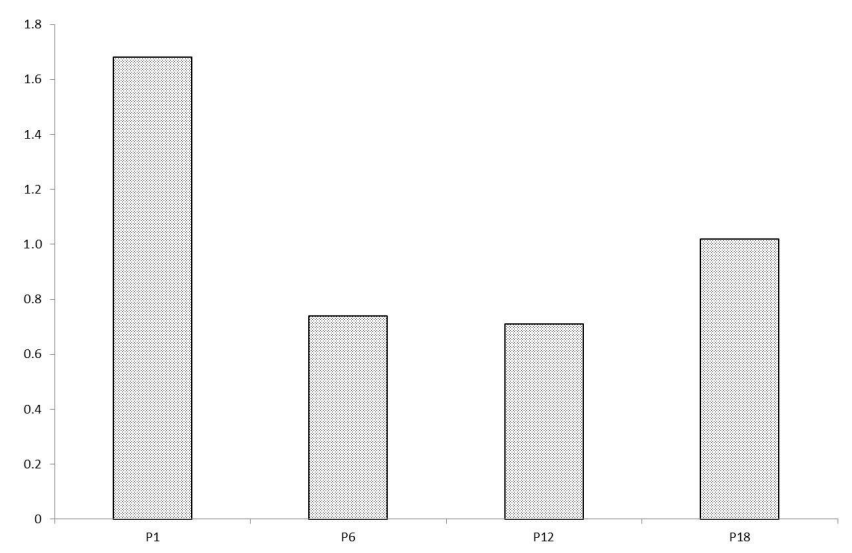

Figure 3. Expression levels of IL- 8 mRNA relative to GAPDH in mouse mammary gland during pregnancy. P1, P6, P12, and P18 = days 1, 6, 12, and 18 of pregnacy, respectively. 


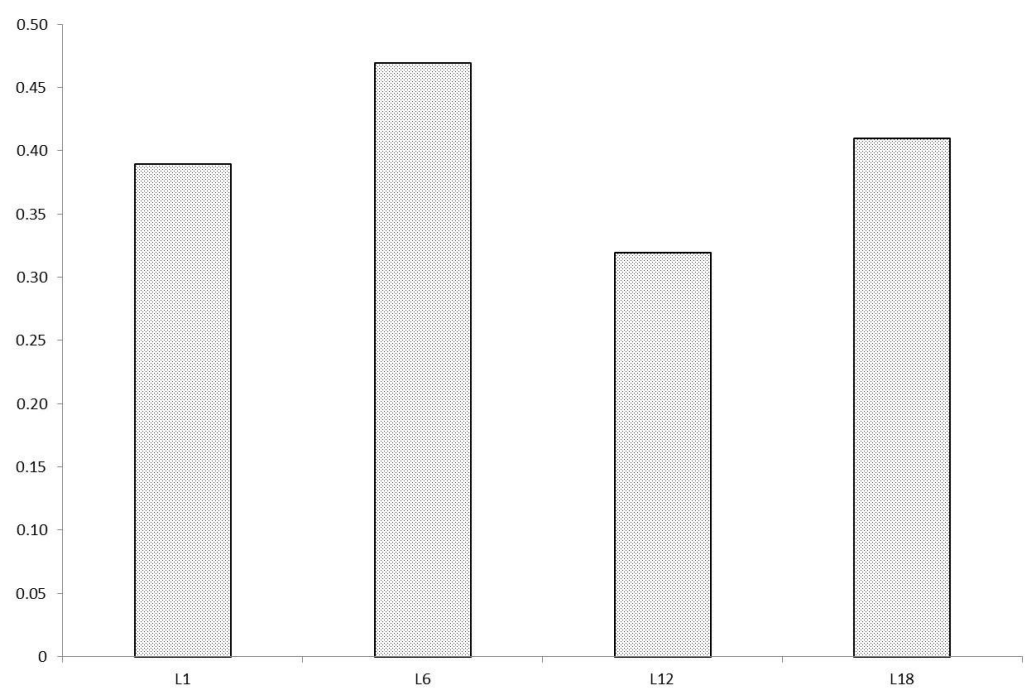

Figure 4. Expression levels of IL-8 mRNA relative to GAPDH in mouse mammary gland during lactation. L1, L6, $\mathrm{L} 12$, and $\mathrm{L} 18=$ days $1,6,12$, and 18 of lactation, respectively.

IL-8 mRNA was highly expressed on day 1 of pregnancy $\left(\mathrm{IL}-8_{\mathrm{IOD}} / \mathrm{GAPDH}_{\mathrm{IOD}}=1.68\right)$ and then suddenly declined, became significant $(\mathrm{P}<0.05)$, and reached 0.74 and 0.71 on days 6 and 12, respectively. On day 18 of pregnancy, expression started to increase (IL- $8_{\text {IOD }} /$ $\left.\mathrm{GAPDH}_{\mathrm{IOD}}=1.02\right)$; however, IL-8 expression levels were not significant $(\mathrm{P}>0.05)$ during days 6, 12 and 18 of pregnancy. During lactation, IL-8 expression levels were lower than those during pregnancy but it stabilized at $0.32-0.41\left(\mathrm{IL}-8_{\mathrm{IOD}} / \mathrm{GAPDH}_{\mathrm{IOD}}\right)$ from days 1 to 18 ; the difference was not significant $(\mathrm{P}>0.05)$.

\section{DISCUSSION}

Recombinant cytokines have been produced to explore their immunomodulatory and therapeutic uses for disease control (Sabroe et al., 2002). IL-8 is an important inflammatory mediator that acts as both a cytokine and a chemokine by recruiting neutrophils to sites of infection and activating them to eliminate pathogens via phagocytosis (Taub and Oppenheim, 1994; Ben-Baruch et al., 1995). However, IL-8 has biological functions in addition to and distinct from its roles in regulating inflammatory responses. IL- 8 has recently been suggested to be closely related to the tumorigenesis, angiogenesis, adhesion, invasion, and metastasis of cancer (Kitadai et al., 1999; Matsuo et al., 2009; Song et al., 2010; Ning et al., 2011; Ju et al., 2012).

IL-8 as marker of peri-implant disease (mucositis and peri-implantitis) has been investigated (Liskmann et al., 2006). Zuccari et al. (2012) have investigated the correlation between IL-8 expression and breast cancer prognosis. The results were statistically correlated with clinicopathological findings. The data reflect the complexity of the role of IL-8 in the tumor microenvironment and support its classification as a possible prognostic marker. IL-8 may be a better indicator of mammary inflammation than of sodium content (Hunt et al., 2012). The content of IL-8 has been quantified to evaluate the effect of temperature on bioactive factors in milk (Ramírez-Santana et 
al., 2012). The mRNA expression of the IL-8 gene in primary bovine mammary epithelial cells as a marker of inflammation has been quantified to evaluate the antibiotic role of a newly developed, engineered multidomain peptide in promoting innate immune responses (Zhu et al., 2012).

IL-8 as an apoptotic, inflammatory, and angiogenic index was measured in patients with breast cancer. Increased IL-8 coincides with the activation of physiologic regulatory mechanisms that attempt to stop tumor cells by inducing apoptosis. The outcompeting of these mechanisms results in tumor progression, as IL-8 is also an angiogenic stimulator (Hamed et al., 2012). Meade et al. (2012) have found that genetic variation in the bovine IL-8 promoter has significant functional implications for IL-8 expression in vitro, which may impact susceptibility to bovine infectious disease and inflammation. However, IL-8 expression, regulation, and function are poorly understood.

We found that IL-8 mRNA was highly expressed in mouse mammary glands on day 1 of pregnancy and then suddenly declined, became significant, and reached similar levels on days 6 and 12. On day 18 of pregnancy, it started to increase but remained lower than the level measured on day 1. IL-8 expressions was not significant during days 6, 12 and 18 of pregnancy. During lactation, IL-8 expression was lower than that during pregnancy but stabilized at $0.32-0.41$ from days 1 to 18 ; the difference was not significant. In mammary biopsies, increased mRNA expression of IL- 8 has been observed in lipopolysaccharide-treated quarters in all groups (Vernay et al., 2012). IL-8 serum levels have been determined and correlated with the clinicopathological features and clinical evolution of mammary gland neoplasias in female dogs. High IL- 8 concentration has been found in mammary gland cancer patients with advanced-stage disease, and Gelaleti et al. (2012) have suggested that IL- 8 can be used as a non-invasive prognostic marker for mammary gland cancer and is useful for the prediction of disease progression and recurrence in dogs with mammary neoplasias.

We found that IL-8 mRNA was expressed throughout pregnancy and lactation, with a marked decrease in expression during pregnancy. During lactation, IL-8 mRNA levels were lower than those during pregnancy, but they stabilized. These sequential changes suggest that IL-8 may act as a cytokine and a chemokine by recruiting neutrophils to mammary glands and activating them to eliminate pathogens via phagocytosis during developmental stages. If this function occurs, it will help us to understand better the mechanisms for the known effect of cytokines on peripubertal mammogenesis. Our results suggest that the variation of IL-8 expression levels during developmental stages may be related to the regulatory role of IL-8 in mouse mammary gland immunity.

\section{ACKNOWLEDGMENTS}

Research supported by the Project of National Major Basic Dairy Research 973 Plan (\#2011CB100802) and by a grant from the Ministry of Agriculture (\#2011-G35).

\section{REFERENCES}

Baggiolini M (2001). Chemokines in pathology and medicine. J. Intern. Med. 250: 91-104.

Baggiolini M, Dewald B and Moser B (1994). Interleukin-8 and related chemotactic cytokines - CXC and CC chemokines. Adv. Immunol. 55: 97-179.

Bek EL, McMillen MA, Scott P, Angus LD, et al. (2002). The effect of diabetes on endothelin, interleukin-8 and vascular endothelial growth factor-mediated angiogenesis in rats. Clin. Sci. 103 (Suppl 48): 424S-429S. 
Ben-Baruch A, Michiel DF and Oppenheim JJ (1995). Signals and receptors involved in recruitment of inflammatory cells. J. Biol. Chem. 270: 11703-11706.

Bruun JM, Verdich C, Toubro S, Astrup A, et al. (2003). Association between measures of insulin sensitivity and circulating levels of interleukin-8, interleukin-6 and tumor necrosis factor-alpha. Effect of weight loss in obese men. Eur. J. Endocrinol. 148: 535-542.

Dinarello CA (1989). Interleukin-1 and its biologically related cytokines. Adv. Immunol. 44: 153-205.

Gelaleti GB, Jardim BV, Leonel C, Moschetta MG, et al. (2012). Interleukin-8 as a prognostic serum marker in canine mammary gland neoplasias. Vet. Immunol. Immunopathol. 146: 106-112.

Hallgren J and Gurish MF (2011). Mast cell progenitor trafficking and maturation. Adv. Exp. Med. Biol. 716: 14-28.

Hamed EA, Zakhary MM and Maximous DW (2012). Apoptosis, angiogenesis, inflammation, and oxidative stress: basic interactions in patients with early and metastatic breast cancer. J. Cancer Res. Clin. Oncol. 138: 999-1009.

Hoffmann E, Dittrich-Breiholz O, Holtmann H and Kracht M (2002). Multiple control of interleukin-8 gene expression. J. Leukoc. Biol. 72: 847-855.

Hunt KM, Williams JE, Shafii B, Hunt MK, et al. (2012). Mastitis Is Associated with Increased Free Fatty Acids, Somatic Cell Count, and Interleukin-8 Concentrations in Human Milk. Breastfeed. Med. [Ahed of Print].

Ju D, Sun D, Xiu L, Meng X, et al. (2012). Interleukin-8 is associated with adhesion, migration and invasion in human gastric cancer SCG-7901 cells. Med. Oncol. 29: 91-99.

Kaplan AP (2001). Chemokines, chemokine receptors and allergy. Int. Arch. Allergy Immunol. 124: 423-431.

Kitadai Y, Takahashi Y, Haruma K, Naka K, et al. (1999). Transfection of interleukin-8 increases angiogenesis and tumorigenesis of human gastric carcinoma cells in nude mice. Br. J. Cancer 81: 647-653.

Koçak H, Oner-Iyidogan Y, Kocak T and Oner P (2004). Determination of diagnostic and prognostic values of urinary interleukin-8, tumor necrosis factor-alpha, and leukocyte arylsulfatase-A activity in patients with bladder cancer. Clin. Biochem. 37: 673-678.

Liskmann S, Vihalemm T, Salum O, Zilmer K, et al. (2006). Correlations between clinical parameters and interleukin-6 and interleukin-10 levels in saliva from totally edentulous patients with peri-implant disease. Int. J. Oral Maxillofac. Implants 21: 543-550.

Matsuo Y, Ochi N, Sawai H, Yasuda A, et al. (2009). CXCL8/IL-8 and CXCL12/SDF-1alpha co-operatively promote invasiveness and angiogenesis in pancreatic cancer. Int. J. Cancer 124: 853-861.

Meade KG, O'Gorman GM, Narciandi F, Machugh DE, et al. (2012). Functional characterisation of bovine interleukin 8 promoter haplotypes in vitro. Mol. Immunol. 50: 108-116.

Ning Y, Manegold PC, Hong YK, Zhang W, et al. (2011). Interleukin-8 is associated with proliferation, migration, angiogenesis and chemosensitivity in vitro and in vivo in colon cancer cell line models. Int. J. Cancer 128: 2038-2049.

Ramírez-Santana C, Perez-Cano FJ, Audi C, Castell M, et al. (2012). Effects of cooling and freezing storage on the stability of bioactive factors in human colostrum. J. Dairy Sci. 95: 2319-2325.

Sabroe I, Lloyd CM, Whyte MK, Dower SK, et al. (2002). Chemokines, innate and adaptive immunity, and respiratory disease. Eur. Respir. J. 19: 350-355.

Sagnak L, Ersoy H, Ozok U, Senturk B, et al. (2009). Predictive value of urinary interleukin-8 cutoff point for recurrences after transurethral resection plus induction bacillus Calmette-Guerin treatment in non-muscle-invasive bladder tumors. Clin. Genitourin. Cancer 7: E16-E23.

Sheryka E, Wheeler MA, Hausladen DA and Weiss RM (2003). Urinary interleukin-8 levels are elevated in subjects with transitional cell carcinoma. Urology 62: 162-166.

Song JH, Kim SG, Jung SA, Lee MK, et al. (2010). The interleukin-8-251 AA genotype is associated with angiogenesis in gastric carcinogenesis in Helicobacter pylori-infected Koreans. Cytokine 51: 158-165.

Sordillo LM and Streicher KL (2002). Mammary gland immunity and mastitis susceptibility. J. Mammary Gland. Biol. Neoplasia 7: 135-146.

Taub DD and Oppenheim JJ (1994). Chemokines, inflammation and the immune system. Ther. Immunol. 1: 229-246.

Vernay MC, Wellnitz O, Kreipe L, van Dorland HA, et al. (2012). Local and systemic response to intramammary lipopolysaccharide challenge during long-term manipulated plasma glucose and insulin concentrations in dairy cows. J. Dairy Sci. 95: 2540-2549.

Zhu YH, Liu PQ, Weng XG, Zhuge ZY, et al. (2012). Short communication: Pheromonicin-SA affects mRNA expression of toll-like receptors, cytokines, and lactoferrin by Staphylococcus aureus-infected bovine mammary epithelial cells. J. Dairy Sci. 95: 759-764.

Zuccari DA, Leonel C, Castro R, Gelaleti GB, et al. (2012). An immunohistochemical study of interleukin-8 (IL-8) in breast cancer. Acta Histochem. 114: 571-576. 